\title{
LOS SENTIDOS DE PERTENENCIA DE LOS Y LAS JÓVENES QUE PARTICIPAN EN EL MOVIMIENTO MASORTÍ EN LA CIUDAD AUTÓNOMA DE BUENOS AIRES. PERCEPCIONES SOBRE EL MOVIMIENTO Y LA "COMUNIDAD"1
} \author{
movement and the "community" \\ por \\ Vanesa Cynthia Lerner* \\ CIS/IDES-CONICET, Argentina \\ vanesalerner@gmail.com
}

Senses of belonging of the young people who take part in the masorti movement in the ciudad autónoma de Buenos Aires. Perceptions on the

\section{Resumen}

En este artículo se analizan los sentidos de pertenencia de los y las jóvenes que participan en el movimiento masortí en la Ciudad Autónoma de Buenos Aires en la actualidad. Sus percepciones sobre el movimiento masortí en general y sobre su “comunidad" en particular muestran que no siempre existe una relación lineal entre ambos. Para ello se utilizó una metodología cualitativa, valiéndose del enfoque interpretativo. Por medio de observaciones participantes y de 32 entrevistas semi-estructuradas realizadas entre febrero de 2016 y septiembre de 2017 se pudo evidenciar el modo en que las dinámicas de centralización y descentralización del movimiento masortí inciden en sus construcciones identitarias.

\footnotetext{
${ }^{1}$ Este artículo forma parte de los resultados de mi tesis de maestría "Construcciones identitarias de los jóvenes que participan en el movimiento conservador/masortí en la Ciudad Autónoma de Buenos Aires en la actualidad", en el marco del proyecto doctoral "El sentido de lo judío en el mundo del judaísmo. Religión, identidad y juventud en el movimiento conservador/masortí argentino en la Ciudad de Buenos Aires en la actualidad" financiado por el Consejo Nacional de Investigaciones Científicas y Técnicas (CONICET), 20152020.

* Licenciada y profesora en Sociología por la Facultad de Ciencias Sociales, Universidad de Buenos Aires. Magíster en Investigación en Ciencias Sociales, Facultad de Ciencias Sociales, Universidad de Buenos Aires. Becaria Interna Doctoral del CONICET.
}

\section{Revista Cultura \& Religión Vol. XIII, 2019 Nº 1 (enero-junio)}

Cómo citar este artículo: Lerner, V.C. (2019). "Los sentidos de pertenencia de los y las jóvenes que participan en el movimiento masortí en la Ciudad Autónoma de Buenos Aires. Percepciones sobre el movimiento y la "comunidad".

Revista Cultura \& Religión. Vol. 13(1). pp. 64-84. 
Palabras clave: sentidos de pertenencia, jóvenes, masortí, comunidad, ciudad autónoma de Buenos Aires.

\begin{abstract}
This article analyzes the senses of belonging of the young people who take part in the masorti movement in the Ciudad Autónoma de Buenos Aires at present. Their perceptions on the masortí movement in general and on their "community" in particular show that not always a linear relation exists between both. For it, it was chosen a qualitative methodology with an interpretive approach. By means of participant observations and 32 semi-structured interviews realized between February, 2016 and September, 2017 it was possible to show the way in which the centralized and decentralized dynamics of the masortí movement affect in their identity constructions.
\end{abstract}

Keywords: senses of belonging, young people, masorti, community, ciudad autónoma de Buenos Aires.

\title{
Introducción.
}

Este artículo tiene como objetivo analizar las percepciones y los sentidos de pertenencia que los y las jóvenes tienen sobre el movimiento masortí en general y sobre su "comunidad" en particular evidenciando que no siempre existe una relación lineal entre ambos.Estos modos de habitar lo masortí permite mostrar aspectos de sus construcciones identitarias.En sintonía con Hall (2011), las mismas nunca están unificadas y, en los tiempos modernos tardíos, aparecen crecientemente fragmentadas y fracturadas; nunca son singulares sino que están construidas a través de diferentes discursos, prácticas y posiciones a menudo intersectadas y antagónicas. Están sujetas a una radical historización, y a un proceso constante de cambio y transformación.

Los conceptos de red de confianza de Tilly (2010) y de comunidad de Bauman (2008) permitirán comprender el modo en que dichos jóvenes construyen su identidad. El primero refiere a que los miembros que la conforman construyen lazos fuertes sometiendo sus relaciones a empresas a largo plazo a riesgo de errores o descuidos de otros miembros de la red. Para que ella exista, la relación tiene que tener un nombre conocido por todos los participantes (una denominación); éstos últimos deben cumplir con un mínimo de derechos y obligaciones; deben tener medios de comunicar y representar su pertenencia compartida; y poder fijar y mantener límites que separan a todos sus miembros de los extraños. El movimiento conservador/masortí puede pensarse de ese modo y los y las jóvenes que participan en él asumen esas características.

\footnotetext{
${ }^{2}$ El movimiento conservador/masortí está compuesto por organizaciones que pueden ser sinagogas o sinagogasescuelas que los actores las llaman "comunidades". El uso de las comillas dobles se utilizará para hacer alusión a las categorías nativas mientras que las comillas simples para dar cuenta de categorías teóricas.
}

\section{Revista Cultura \& Religión Vol. XIII, 2019 № 1 (enero-junio)}

Cómo citar este artículo: Lerner, V.C. (2019). "Los sentidos de pertenencia de los y las jóvenes que participan en el movimiento masortí en la Ciudad Autónoma de Buenos Aires. Percepciones sobre el movimiento y la "comunidad". Revista Cultura \& Religión. Vol. 13(1). pp. 64-84. 
El segundo, es entendido como una evocación de significados vinculado con lo bueno, lo cálido y lo apacible. Apela a "algo que siempre ha sido". Esta comunidad posmoderna poco tiene que ver con la idea de comunidad de Tönnies y Redfield caracterizada por tener un entendimiento compartido "tácito" y "natural". Por ser pequeña, distintiva y autosuficiente (Bauman, 2008). Ese tipo de comunidad cae cuando se hace autoconsciente, cuando se la nombra, se la pregona y se la critica. Aunque ya no logra establecer una frontera tajante entre un "nosotros" y un "otros", mantener el monopolio de la comunicación y permanecer aislada del mundo externo, opera como si esto efectivamente sucediera. Los actores la imaginan y la construyen artificialmente. La unidad y la homogeneidad son elegidas y construidas ante una variedad de ofertas. Y, aunque la comunidad existente sufra conflictos en su interior o amenazas del mundo externo, en la comunidad imaginada hallarán ese paraíso perdido. La comunidad siempre es frágil y vulnerable por lo que necesitará vigilancia, fortificación y defensa para sostenerse a sí misma.

De acuerdo con varios autores y autoras, la identidad judía incluye una multiplicidad de dimensiones (ideológicas, religiosas, culturales, étnicas, nacionales, políticas, lingüísticas, idiomáticas y geográficas), que, redefinidas desde la significación particular de cada sujeto, otorgan al judaísmo una representación multifacética (Erdei, 2011; Caro, 2006; Baumann, 2001). Lo religioso constituye así una de las dimensiones que comprende a las identificaciones con lo judío cuyo peso es significativo. En torno a su eje, los actores sociales sostienen la existencia de tres corrientes: la neo-ortodoxa, la reformista y la conservadora/masortí. Esta última se definió a sí misma como una tercera posición entre las otras dos ya que "conservaba" el cumplimiento de la Ley Judía al igual que la primera, pero adaptándose a la realidad circundante como la segunda. También es llamada tradicionalista (masoret/masortí) por continuar con las tradiciones. Ejemplos de esto es que cumple con el precepto del Shabat -Sábado, día sagrado de la semana que comienza el viernes cuando sale la primera estrella y termina el sábado cuando la misma vuelve a salir- pero permite que la feligresía viaje y utilice dinero para acercarse a la sinagoga, que hombres y mujeres compartan el mismo espacio físico en las ceremonias religiosas, la utilización de instrumentos musicales y micrófonos en los servicios religiosos, el uso del idioma vernáculo en el recitado de plegarias, la ordenación de rabinas mujeres, etc.

El movimiento conservador/masortí se originó en Europa Occidental a mediados del siglo XIX, tras los avances del Iluminismo y la constitución de los Estados-Nación en ese entonces conocido como corriente judeo-histórica positiva. Bajo los pilares de la razón, entendía que el estudio y la formación de rabinos y de intelectuales no debían estar circunscriptos al estudio de la Biblia y del Talmud, sino también a una variedad de saberes tales como: textos afines a la exégesis del texto bíblico (midrash), filosofía, liturgia, poesía medieval, teología moderna y literatura hebrea moderna. Su institucionalización se dio en los Estados Unidos a fines XIX siendo el Jewish Theological Seminary of America el referente académico e ideológico. En el caso argentino, éste se comenzó a conformar en 1957 cuando la Congregación Israelita de la República Argentina (CIRA), quien adhería a la corriente reformista europea, decidió unirse a la United Synagoges of America. Así, en 1959 el rabino

\section{Revista Cultura \& Religión Vol. XIII, 2019 Nº 1 (enero-junio)}

Cómo citar este artículo: Lerner, V.C. (2019). "Los sentidos de pertenencia de los y las jóvenes que participan en el movimiento masortí en la Ciudad Autónoma de Buenos Aires. Percepciones sobre el movimiento y la "comunidad".

Revista Cultura \& Religión. Vol. 13(1). pp. 64-84. 
conservador estadounidense Marshall T. Meyer egresado de Jewish Teological Seminary llegó a dicho país para hacerse cargo de la organización, convirtiéndose en su principal referente (Schenquer 2012).

Tanto Rosemberg (2010) como Fainstein (2006) han realizado investigaciones sobre el origen de dicho movimiento haciendo hincapié en su liderazgo. Incluso Weil (1988) reconstruyó su surgimiento en Argentina desde una perspectiva militante. Por su parte, Laikin Elkin (1986) también analizó el surgimiento dando cuenta de los cambios que estaba teniendo a partir de la crisis del Estado de Israel como principal fuente de identificación junto con el crecimiento de la neo-ortodoxia en Argentina y en América Latina, lo cual coincide con lo esbozado por Rubel (2011) y Bokser Liwerant (2011) quienes manifestaron la pluralización del campo religioso en el judaísmo al igual que lo hizo Senkman (2007). Asimismo, Melamed (2000) planteó la crisis de la Asociación Mutual Israelita Argentina (AMIA) como principal organizador del movimiento junto con la crisis comunitaria tras las consecuencias del modelo neoliberal acordando en esto último con DellaPérgola (2011). A su vez, Jozami, Bargman y Bialogorski (1998) a través de un trabajo comparativo entre los colectivos coreano, árabe y judío dieron cuenta de sus procesos migratorios, su integración y su reconfiguración identitaria en el presente. En el caso judío puede notarse esa pluralidad en el campo religioso y cómo la crisis de la AMIA los ha interpelado. Schenquer (2012) abordó las actitudes sociales de las dirigencias de la Delegación de Asociaciones Israelitas Argentinas (DAIA) y de las organizaciones judías religiosas liberales durante la última dictadura militar argentina (1976-1983). Su trabajo no solo permite reconstruir el origen del movimiento conservador/masortí sino también exponer cómo aspectos de su institucionalización siguen vigentes en la construcción identitaria de los jóvenes en el presente, aunque estos últimos no hayan sido la población de interés. Chami Paz, Scundieri e Imhoff (2018) exploraron algunos aspectos de la identidad social de jóvenes en el marco de la educación formal conservadora/masortí en Córdoba, Argentina en la actualidad lo cual resulta complementario para pensar la educación no formal y explicitar la presencia de distintos espacios de socialización. A la vez, identificar el modo en que los actores construyen fronteras hacia un "afuera" no judío.

Además, existen investigaciones que indagaron sobre la identidad judía y han incluido la dimensión religiosa en su análisis evidenciando sus transformaciones con los procesos posmodernos en Cataluña, Madrid, Santiago de Chile, Lima, etc. (Martínez Ariño, 2011; Camargo Crespo; 1999; Kornbluth Nachtygal, 2012; Yalonetzky Mankevich, 2016). Igualmente, en Argentina (Setton, 2015; Hupert, 2014; Brauner, 2009; Jmelnizky \& Erdei, 2005; Álvarez \& Strusberg, 2003).

Indagar esta cuestión implicaría dar cuenta de cómo los jóvenes reconstruyen su identificación con lo judío siendo un aporte para el campo de la Sociología de la Religión. La preocupación de esta disciplina por los jóvenes está presente en la producción académica latinoamericana de este último tiempo principalmente en las religiones cristianas (Mosqueira, 2014; Martínez Lozano \& Solís Domínguez, 2009; Romero Ocampo, 2010). Así, el estudio

\section{Revista Cultura \& Religión Vol. XIII, 2019 Nº 1 (enero-junio)}

Cómo citar este artículo: Lerner, V.C. (2019). "Los sentidos de pertenencia de los y las jóvenes que participan en el movimiento masortí en la Ciudad Autónoma de Buenos Aires. Percepciones sobre el movimiento y la "comunidad". Revista Cultura \& Religión. Vol. 13(1). pp. 64-84. 
de jóvenes que pertenecen o participan en minorías religiosas, permitirá en un futuro, comparar dinámicas sociales estableciendo similitudes y diferencias.

\section{Metodología.}

Esta investigación cualitativa se valió del enfoque interpretativo como perspectiva conceptual dentro de la investigación sociológica ya que éste se centra primariamente en los aspectos simbólicos de la vida social y en los significados de la vida individual (Sautu, 1999). En el mundo de la interpretación subjetiva del sentido, se considera importante la comprensión de la acción social como sentido que el actor asigna a su acción (Schutz, 1974).

Se tomó como unidad de análisis a los y las jóvenes que participan como educadores y educadoras no formales en los distintos Departamentos de Juventud de las "comunidades" que adhieren al movimiento conservador/masortí y están asociadas a la organización Noam Argentina ${ }^{3}$ ubicados en la Ciudad Autónoma de Buenos Aires. A estos y estas jóvenes se los llamó emprendedores de una moral masortí, concepto tomado de Howard Becker (2014). A partir de sus actividades, de su hacer, ponen en práctica 'iniciativas morales' mostrando qué es lo correcto y lo incorrecto de acuerdo con el código masortí. Esta categoría incluye a los secretarios y secretarias o en hebreo mazkirim/mazkirot a cargo de la dirección de Noam así como a los diferentes escalafones que conforman los Departamentos de Juventud: los directores y directoras, los y las representantes del "Área de Juventud" ante las Comisiones Directivas, los coordinadores y las coordinadoras a cargo de las áreas divididas en jardín de infantes, primaria y secundaria, el coordinador o coordinadora educativo/a o en hebreo rosh jinuj, el director o directora y el profesor o profesora del "curso de madrijim " y los madrijim y madrijot o los líderes y lideresas encargados de desarrollar las actividades para sus janijim/janijot o educandos (Freire, 2005) los días sábados. Tanto los educandos como los

\footnotetext{
${ }^{3}$ Noam Argentina forma parte de Noam Olami. Ésta es una de las organizaciones mundiales que conforma al nodo "juventud" dentro del movimiento. Se encarga de promover la educación no formal a nivel mundial a niños y adolescentes entre 8 y 18 años. Su sede central está en los Estados Unidos, con filiales en diferentes países. En el caso de Argentina, el movimiento conservador/masortí registró la existencia de 37 "comunidades" que adhieren a él siendo un número significativo en comparación con otros países, de las cuales 16 con Departamentos de Juventud forman parte de Noam (Amijai, Bet-El, Bet Hilel, Benei Tikvá, Beit Israel, Bialik de Devoto, Or Jadash, Dor Jadash, Comunidad Pardés, Lamroth ha Kol, Sio de Morón, Tfilat Shalom, Comunidad Jerusalén, Juventud Judaica, Ciso de Ramos Mejía y Ioná). Todas ellas están ubicadas en la Ciudad Autónoma de Buenos Aires y en el Gran Buenos Aires. Si bien en el interior del país existen "comunidades" y organizaciones juveniles cuya espiritualidad es conservadora/masortí, no se encuentran adheridas a Noam sino a los movimientos juveniles sionistas. Cabe aclarar que dentro del mundo juvenil judío, el movimiento conservador/masortí no es el único en desarrollar la educación no formal. Existen otras organizaciones judías religiosas y laicas donde también se la lleva a cabo. Ejemplos de ellas son: las entidades sociodeportivas adheridas a la Federación Argentina de Centros Comunitarios Macabeos (FACCMA), las asociadas al Movimiento Juvenil Sionista y al Idisher Cultur Farband (ICUF). Asimismo, se encuentra la Fundación Bamá (Beit Hamejanej Haiehudí - La casa del Educador Judío), quien también promueve la educación tanto formal como no formal en las organizaciones judeo-argentinas.
}

\section{Revista Cultura \& Religión Vol. XIII, 2019 № 1 (enero-junio)}

Cómo citar este artículo: Lerner, V.C. (2019). "Los sentidos de pertenencia de los y las jóvenes que participan en el movimiento masortí en la Ciudad Autónoma de Buenos Aires. Percepciones sobre el movimiento y la "comunidad". Revista Cultura \& Religión. Vol. 13(1). pp. 64-84. 
voluntarios, voluntarias, los rabinos, las rabinas, los cantores, cantoras y seminaristas quedaron por fuera de la categoría de emprendedores. Solo se contó a aquellos voluntarios que trabajan dentro de los Departamentos de Juventud.

Tratándose de una investigación que no buscó representatividad estadística, el muestreo se basó en criterios de tipo teórico través de la técnica "Bola de nieve". Se realizó entre febrero de 2016 y septiembre de 2017, 32 entrevistas semi-estructuradas a jóvenes de cinco "comunidades" que participan dentro de la educación no formal. Los ejes de indagación fueron: trayectorias, interacciones y circuitos dentro del movimiento masortí; las representaciones de las y los jóvenes sobre Israel y el conflicto de Medio Oriente, la Shoá, las fechas patrias y temas de actualidad argentina, la transmisión del contenido judío (relatos bíblicos, símbolos costumbres) y valores en sus actividades; $\mathrm{y}$, los sentidos de pertenencia sobre el movimiento masortí.

Aparte, ya contaba con una entrevista que había llevado a cabo en abril de 2011 al secretario de Noam y con observaciones participantes de cursos, congresos, actividades dirigidas a jóvenes, etc. Dichas técnicas de recolección de datos permitieron recuperar la voz de los actores e indagar en sus representaciones y relatos biográficos tratando de buscar flexibilidad sin dejar de desarrollar las ideas de la investigadora (Denscombe, 1999). También se hicieron observaciones en una "comunidad" en particular entre noviembre y diciembre de 2016 y marzo de 2017. La guía de observación estuvo compuesta por los siguientes puntos: dinámica de trabajo (grupal, individual); uso del espacio; temas que se trataban en la reunión; vínculos interpersonales entre los y las jóvenes y duración de los encuentros.

De los madrijim y madrijot entrevistados, 20 egresaron o estaban cursando su último año en escuelas secundarias privadas judías mientras que 5 fueron a escuelas secundarias públicas y 5 a escuelas privadas laicas (hay dos casos perdidos). No obstante, 25 estudiaban, iban a estudiar o estudiaron alguna carrera de grado o terciario en entidades públicas. Salvo 3 casos, el resto vivía con sus padres que en su mayoría eran profesionales y comerciantes. La mitad participaba en forma activa en su "comunidad", ya sea a partir de prácticas voluntarias y cursos de estudio mientras que el resto solo asistía a los servicios religiosos durante las fiestas del Año Nuevo Judío y del Día del Perdón. Mas no se trató de una muestra probabilística, se notó que la decisión de los y las jóvenes de participar en un ámbito "comunitario" no estaba vinculada con el actual involucramiento de sus padres. Incluso, algunos líderes y lideresas comentaron que fueron ellos quienes estando sus padres alejados de la vida judía llevaron el judaísmo a sus casas.

Los rangos de edad de este grupo fueron entre 17 a 32 años; la media de edad, 20,3; la moda, 19 años, la mediana, 22 años; el desvío estándar, 3,79. La muestra se conformó de 21 mujeres y 11 varones. Cabe aclarar que estos son datos descriptivos. Lo juvenil no fue pensado como un dato biológico objetivo sino como constructo histórico, social y cultural, configurándose diferentes modos de ser joven en cada período histórico y en cada posición de un mismo espacio-tiempo social. La edad, pues, se construye por las condiciones de existencia en las que está inserto cada sujeto (Bourdieu, 1990). En este sentido, lo "juvenil"

\section{Revista Cultura \& Religión Vol. XIII, 2019 Nº 1 (enero-junio)}

Cómo citar este artículo: Lerner, V.C. (2019). "Los sentidos de pertenencia de los y las jóvenes que participan en el movimiento masortí en la Ciudad Autónoma de Buenos Aires. Percepciones sobre el movimiento y la "comunidad".

Revista Cultura \& Religión. Vol. 13(1). pp. 64-84. 
es un concepto relacional, que cobra sentido contextualmente al interior de relaciones de poder y en interacción con categorías extra-juveniles como las de clase social, género, etnia, entre otras. Por lo tanto, la juventud no debe ser pensada como un grupo social continuo y ahistórico, sino dinámico y discontinuo, donde los jóvenes y las jóvenes constituyen una categoría heterogénea, tanto diacrónica como sincrónicamente. No se puede hablar de un tipo de juventud sino de juventudes (Reguillo Cruz, 2000).

Todos los nombres de las "comunidades" y de las personas entrevistadas son ficticios para preservar su anonimato de modo que cualquier similitud con la realidad es pura coincidencia.

\section{Resultados}

\section{2. ¿Quién es esta juventud?}

Los y las jóvenes dan cuenta de la existencia de una trayectoria o una carrera que los lleva a ejercer este rol de educador no formal. Primero se empieza como educando o janij. Se asiste a las actividades y se participa de las propuestas pedagógicas que ofrece el madrij o madrijá que en hebreo significa líder, lideresa o guía, encargados de transmitir a sus educandos valores de convivencia, respeto, contenidos judaicos, costumbres.

Para poder ser educador es necesario hacer un curso de formación. Al igual que los rabinos y rabinas, los madrijimy madrijot, una vez egresados de estos cursos, pasan a ser considerados especialistas dentro del mundo masortí ya que adquieren capitales simbólicos y religiosos (Bourdieu, 2006). Al mismo tiempo que van incorporando experiencia como educadores, pueden ser convocados por la "comunidad" para realizar el "curso de Nofim" en el Seminario Rabínico Latinoamericano que los habilita a coordinar o dirigir algunas de las áreas (Jardín, Primaria, Secundaria) y por lo tanto tener a cargo a un grupo de madrijim y madrijot. Luego de ejercer como coordinadores/as en los Departamentos de Juventud de sus "comunidades" podrán aplicar a la dirección. Como vemos, la formación para ser educador no formal, del mismo modo que la formal, se encuentra pautada por instancias que certifican la adquisición de habilidades para ocupar cargos organizados jerárquicamente dentro de una estructura institucional.

En la definición que estos emprendedores y emprendedoras hacen de sí mismos explican que se trata de personas que por medio de la educación no formal, son los encargados de transmitir saberes del judaísmo a partir de diferentes recursos, entre ellos los lúdicos. En dichos saberes pueden encontrarse valores, leyes y reglas que según Becker (2014) se diferencian de acuerdo con el grado de ambigüedad. Los valores son una guía vaga para la acción general pero que para los individuos no resultan útiles para decidir acciones concretas. En ese caso, los mismos elaboran reglas específicas más cercanas a la realidad de la vida cotidiana. Se trata de costumbres de un grupo que son más precisas que los valores, pero no tanto como las leyes pues dichas reglas comprenden vastas zonas que habilitan a un amplio espectro de interpretaciones. No obstante, los valores son las premisas fundamentales

\section{Revista Cultura \& Religión Vol. XIII, 2019 № 1 (enero-junio)}

Cómo citar este artículo: Lerner, V.C. (2019). "Los sentidos de pertenencia de los y las jóvenes que participan en el movimiento masortí en la Ciudad Autónoma de Buenos Aires. Percepciones sobre el movimiento y la "comunidad".

Revista Cultura \& Religión. Vol. 13(1). pp. 64-84. 
de las que se deducen normas específicas, siendo su tipo ideal la ley. Esta última se diferencia de las anteriores por su precisión. Se sabe con bastante grado de certeza qué se puede y que no se puede hacer. En el próximo apartado se desarrollará el modo en que se ponen en práctica.

Los y las jóvenes son expertos dentro del mundo masortí por haberse formado y por tener una trayectoria "comunitaria" que comenzó en su niñez o en su adolescencia. Este recorrido por la educación no formal pudo haberse dado en una sola "comunidad" o como se dio en la mayoría de los casos, se trató de una circulación sucesiva por diferentes "comunidades" o clubes hasta dar con ese espacio.

Se trata de una juventud específica que participa allí a partir de un trabajo voluntario escasamente remunerado. La educación no formal resulta ser la forma institucionalizada que encuentran las "comunidades" para hacer partícipe al joven. En su mayoría, dichos jóvenes atraviesan un proceso de transición hacia la vida adulta. De hecho, según sus testimonios, las razones por las cuales se abandona esta labor se deben a que en la medida en que van asumiendo más responsabilidades (estudio, trabajo, etc.) disponen de menos tiempo. Es un momento en el que están terminando su escuela secundaria o iniciando sus carreras universitarias. Son jóvenes que estudian, que trabajan pocas horas, tienen sus pasatiempos, viven con sus padres y no tienen hijos. Por lo tanto, en términos de Margulis y Urresti (2008) esta juventud responde a un sector social particular (sectores medios, medios-altos), permitiéndoles gozar de un período de menor exigencia antes de ingresar a la adultez. Insertarse siendo joven en la "comunidad" por fuera del Departamento de Juventud resulta dificultoso ya que ésta no ofrece espacios para ese nicho. Si bien varias organizaciones están tratando de generarlos, el proceso es muy incipiente. De este modo, los jóvenes saben que ejercerán esa labor por un tiempo determinado.

\section{Percepciones de los jóvenes sobre el movimiento masortí: identificaciones y conflictos.}

El movimiento conservador/masortí es un movimiento trasnacional cuyo centro se encuentra en los Estados Unidos por haber sido su lugar de institucionalización. Tiene presencia en Israel, Canadá, América Latina y El Caribe, Francia, España, Gran Bretaña, Alemania, Ucrania, Uganda y Australia. Pueden distinguirse suborganizaciones o nodos que lo componen, conformando de este modo una red o en términos de Charles Tilly (2010), una red de confianza ${ }^{4}$.

\footnotetext{
${ }^{4}$ Como ya se explicó existe un nodo "juventud" que incluye a Noam y a otras organizaciones. Hay un nodo "académico" compuesto por entidades de formación rabínica, docente y de cantores. Ejemplo de ellas son: el Jewish Theological Seminary de Nueva York anteriormente nombrada, la ZieglerSchool of Rabbinic Studys of the American Jewish University en Los Ángeles, el Majón Schejter en Israel y el Seminario Rabínico Latinoamericano en Buenos Aires. Por su parte, está el nodo de los "graduados", que quienes participan son los egresados de las entidades anteriormente nombradas. La organización más emblemática es la Rabbinical
} 
Después de miles de años las redes de confianza siguen floreciendo en el siglo XXI. Los individuos las crean y las recrean todo el tiempo, formando solidaridades perdurables. Dichas redes crean controles para evitar transgresiones y errores. Su pertenencia no garantiza la felicidad ni la libertad. No obstante, sus miembros reciben compensaciones por su conformidad a través de la atención personal, ayuda, reciprocidad a largo plazo, protección contra posibles desastres o incapacidades y beneficios que por lo general no pueden conseguir en otra parte. Para que esta red de confianza funcione es necesario favorecer la intimidad entre sus nodos. En el caso del movimiento masortí, pueden encontrarse nodos a escala global, regional y local. Los emprendedores y emprendedoras daban cuenta de su existencia, aunque ellos en su cotidianeidad establecen lazos fuertes y ponen recursos para llevar una empresa a largo plazo en su nodo local, es decir, en sus respectivas "comunidades". De este modo, podría decirse que dicha intimidad estaría presente.

Los emprendedores y emprendedoras muestran que el movimiento masortí argentino tiene sus especificidades que claramente lo diferencian de los nodos masortí de Israel o de los Estados Unidos. En esos lugares, el cumplimiento de la Ley Judía no se desdobla entre lo público-privado. La feligresía israelí y estadounidense se apropia de los preceptos tanto en "comunidad" como fuera de ella. En cambio, en Argentina lo masortí se recrea mayoritariamente en exclusiva en el ámbito "comunitario". Dichas esferas son independientes y están claramente definidas. Entienden que en primera instancia su vida religiosa es descentralizada: lo masortí es habitado en "comunidad" es decir, de modo insular. Podría decirse que dentro del movimiento masortí también existen 'comunitarismos' como puede verse en Giménez Béliveau (2016) en el campo católico argentino o en Carozzi (1999) donde los new agers circulan por diferentes comunidades y desarrollan su individualidad a partir de lo aprehendido en las mismas.

En cuanto al sistema normativo, es el Committee on Jewish Law and Standards de la Rabbinical Assembly ubicada en los Estados Unidos quien se encarga de establecer y de modificar las leyes siendo éstas las posiciones legales oficiales de los rabinos y rabinas del movimiento. Es el que centraliza y ejerce 'el régimen institucional de la validación del creer' a partir de un sistema normativo definido por autoridades que resulta estable para los fieles (Hervieu-Léger, 2004). Sin embargo, esto no implica que al interior de cada organización que adhiere a dicho movimiento se desarrolle una autonomía relativa aplicando 'regímenes de validación comunitaria del creer' que responden "al deseo de grupos particulares de vivir su fe de forma intensiva (...) que comparten una interpretación común de la relación con el mundo y del modo de vida que implica la posesión de la verdad" (Hervieu-Léger, 2004,

Assembly ubicada en Nueva York. Y, un nodo "político" conformado por United Synagogue of Conservative Judaism, organización que representa a las sinagogas adheridas al mismo; Mercaz quien defiende los intereses del judaísmo conservador/masortí en la Organización Sionista Mundial y en la Agencia Judía; y The World Council of Conservative/ Masorti Synagogues (Masorti Olami) que se ocupa de los asuntos del movimiento a nivel mundial siendo su referente local la Federación de Comunidades del Judaísmo Conservador (FEDECC) que vela por las organizaciones conservadoras en Argentina. Entre estas dos entidades se encuentra Masortí Amlat cuya función es la misma a nivel regional, es decir, en América Latina. Se denominó a los nodos de acuerdo a las categorías nativas utilizadas por los actores del movimiento.

\section{Revista Cultura \& Religión Vol. XIII, 2019 N 1 (enero-junio)}

Cómo citar este artículo: Lerner, V.C. (2019). "Los sentidos de pertenencia de los y las jóvenes que participan en el movimiento masortí en la Ciudad Autónoma de Buenos Aires. Percepciones sobre el movimiento y la "comunidad". Revista Cultura \& Religión. Vol. 13(1). pp. 64-84. 
p.192). Esto es así ya que los rabinos y rabinas en sus respectivas "comunidades" poseen la autoridad máxima (marei d'atra) en cuanto lo religioso. Pueden decidir sobre el cumplimiento de los preceptos y la forma de aplicarlos, pero no pueden inventar responsas nuevas. No obstante, en la práctica se da un doble poder. La aplicación de la Ley Judía es producto de una negociación entre éstos con las Comisiones Directivas que detentan el poder económico. Las fronteras entre el poder religioso y económico son poco claras para definir lo sagrado y lo profano. Simultáneamente, existe una historia institucional en cuanto a la aplicación de la Ley Judía que trasciende a la figura religiosa. De este modo, si el rabino o rabina quisiera incorporar cambios debería tener en cuenta estas cuestiones. Los emprendedores y emprendedoras eran conscientes de estos procesos. Ellos y ellas aplican y hacen aplicar leyes y reglas teniendo en cuenta a la autoridad rabínica y la tradición institucional, notando que cada "comunidad" se apropia de la Ley Judía a su manera. Aunque el movimiento masortí avale esta descentralización y esta autonomía relativa respecto de la aplicación de la Ley, para los y las jóvenes resulta ser un conflicto para pensarse como movimiento.

Los aspectos centralizadores del movimiento aparecen en los entrevistados cuando comparten mismos espacios, por ejemplo: cursos, capacitaciones, campamentos, días de trabajo en conjunto, acordar puntos de encuentro para ir a algún acto. Los rituales religiosos (ceremonias de Shabat, Havdalá, encendido de las velas de Jánuca) cobran un sentido de pertenencia que trasciende a las particularidades de las "comunidades". Reconocen que forman parte del movimiento masortí primero en el hecho de estar o activar en una "comunidad" y luego en la unión entre "comunidades". Sin embargo, los vínculos "intercomunitarios" no siempre resultan armoniosos. Si bien Noam tiene la función de centralizar a los departamentos que están en el movimiento masortí, en la práctica, cada vínculo Noam-Departamento de Juventud, tiene su propia especificidad que estará dada de acuerdo con las necesidades económicas de cada "comunidad" o al tipo de afinidad que rabinos, rabinas, directores y directoras tengan con Noam.

Salvo un caso, todos se sienten identificados con el movimiento masortí. Lo reconocen en tanto denominación, lo definen como plural, flexible con un amplio espectro. Fundamentan que esto es así ya que adapta la Ley Judía a la actualidad y que en su apropiación pueden existir diferentes formas de aplicarla. La premisa "Tradición y Cambio" resulta recurrente. Los emprendedores y emprendedoras acuden a "otros" (la neo-ortodoxia caracterizada por cumplir rigurosamente con los preceptos religiosos y el reformismo que por el contrario deja de lado el cumplimiento de la Ley Judía apelando a la autonomía individual) para definir a su movimiento. Rescatan su posicionamiento democrático y su espíritu crítico. Valoran la existencia de diferentes formas de apropiación de preceptos y diversas posturas ante dilemas éticos.

Lo que más les atrae del movimiento masortí es la posibilidad de elegir. Expresan un sentimiento de libertad, cuando eligen qué respetar lo hacen con una "intención" particular. El precepto o la costumbre que deciden cumplir tienen una trascendencia porque realmente se sienten implicados con esa acción. Frases tales como "hago las cosas como las siento",

\section{Revista Cultura \& Religión Vol. XIII, 2019 Nº 1 (enero-junio)}

Cómo citar este artículo: Lerner, V.C. (2019). "Los sentidos de pertenencia de los y las jóvenes que participan en el movimiento masortí en la Ciudad Autónoma de Buenos Aires. Percepciones sobre el movimiento y la "comunidad".

Revista Cultura \& Religión. Vol. 13(1). pp. 64-84. 
“armo mi propio estilo de vida", "puedo elegir a mi manera”, resultan recurrentes. Están de acuerdo en poder construirse a sí mismos.

Lo que encuentro en el movimiento conservador que no encuentro en ningún otro es lo que yo doy en

"Talmud Torá" (curso de preparación para llevar a cabo las ceremonias de Bat y Bar Mitzvá) por ejemplo. Armás tu estilo de vida judía como vos quieras. Es eso para mí es clave (...) yo propongo, yo promuevo que armen su vida, que no sea una bajada de línea (Entrevista a Malena, madrijá y maestra de "Talmud Torá" de Comunidad Menorá, 20 años, 1 de diciembre de 2016).

E:- ¿Cuáles son los preceptos que te hacen sentir parte del movimiento masortí?

K:- O sea, no, por ejemplo, sé que en Comunidad Shalom se come kasher y todo eso pero no es lo que más me guía sino la idea de entender al judaísmo como una forma de vida y poder, la idea de la importancia de la transmisión, de amar al prójimo como a vos mismo, el tema del respeto, del trato, de la convivencia, no sé tanto a nivel de preceptos, sí a nivel de valores (...) Por ejemplo en el hecho de estar en una comunidad, de ser parte de una comunidad, de llevar una vida de judío (Entrevista a Karen, egresada del "curso de madrijim" de Comunidad Shalom, 19 años, 26 de diciembre de 2016).

En este punto, los debates de Frigerio (2016) y Ceriani (2013) sobre la religión y lo espiritual como categorías sociales, permiten reflexionar sobre estas cuestiones. Ceriani (2013) explica que la categoría religión es una construcción moderna. Siguiendo a Frigerio (2016) la misma remite a las relaciones institucionales y las creencias compartidas. Incluye dimensiones externas tales como: edificios, instituciones, profesionales religiosos, símbolos, rituales sagrados y "un Dios que está allí afuera”. Por el contrario, lo espiritual está vinculado a una dimensión interna, subjetiva, experiencial, emocional, con un Dios interior. Asimismo, Frigerio (2016) agrega que aquellos sujetos que defienden la espiritualidad por sobre la religión, la entienden como una "actitud" frente a la fuente legítima de la autoridad religiosa donde cada individuo funciona como árbitro. Puede evidenciarse que los y las jóvenes definen al movimiento conservador/masortí utilizando categorías que exceden a la religión y que está relacionado con su estilo de vida secular.

Al mismo tiempo, esta pluralidad en la vida religiosa masortí resulta conflictiva. Pueden notarse posiciones ambivalentes en sus discursos. Por momentos sienten la necesidad de tener definiciones claras y cerradas. Están de acuerdo con que la Ley Judía se adapte a su estilo de vida secular, pero también creen que su apropiación es selectiva, irracional y arbitraria. Notan una distancia entre el discurso masortí y la práctica de la feligresía. En las definiciones de los jóvenes aparecen expresiones tales como "avenida del medio", "limbo", "arma de doble filo", "difuso", "poco claro", "algo que está y no está definido", "el que mucho abarca poco aprieta". En algunos casos hay una necesidad de definir qué es el movimiento masortí y se cree que la observancia de preceptos debe ser mayor para alcanzar una mayor coherencia y así tener una mayor credibilidad.

E:- ¿Y vos qué pensás del movimiento masortí?

K:- Yo creo que es un arma de doble filo. Es una espada de doble filo (...) lo masortí es algo que está definido y no está definido. Es algo que es y es algo que no es. Es algo que está y no está, es algo que tienen límites y que no tiene. Hay un masortí que te puede decir que el matrimonio igualitario está bien

\section{Revista Cultura \& Religión Vol. XIII, 2019 № 1 (enero-junio)}

Cómo citar este artículo: Lerner, V.C. (2019). "Los sentidos de pertenencia de los y las jóvenes que participan en el movimiento masortí en la Ciudad Autónoma de Buenos Aires. Percepciones sobre el movimiento y la "comunidad".

Revista Cultura \& Religión. Vol. 13(1). pp. 64-84. 
y otro que te va a decir que está mal y otro que te va a decir que en Shabat se puede escribir porque eso no implica un esfuerzo y otro te va decir que no. Como que hay muchas interpretaciones y un poco el movimiento masortí en Argentina quizás frente a esta diversidad pierde un poco la claridad, que es lo real, que pierde esto. Frente a la masificación, como lo de Noam, frente a la masificación pierde su esencia (...) yo lo vivo más como el judaísmo en general. Como que lo llevo a una manera de pensar, a una manera de ser, a una manera de comportarse, no solo de prácticas. Yo soy judío tradicionalista, tipo que festejo Pesaj y festejo Iom Kipur y todas esas tradiciones las cumplo pero hay otra gente que no. Pero yo, yo vivo mi judaísmo más allá de esas tradiciones, yo vivo el judaísmo porque es una manera de pensar, de ser. Lo masortí permite mucho esto. Admite mucho la crítica al judaísmo y la crítica constructiva y la crítica destructiva también pero la crítica en sí. Lo que genera es esto, poder abrir la cabeza y poder pensar un poco más allá de lo que es como para entender un poco más la realidad que existe hoy. Que hay muchas opciones, que no se cierra en una (Entrevista a Kevin, madrij de Comunidad Shalom, 21 años, 19 de junio de 2017).

Los discursos están atravesados por una lógica de revitalización de la halajá (Ley Judía). Incluso, a partir de los relatos de sus mayores los emprendedores dicen que en la década de 1990 se cumplía menos que ahora. Ese período, resulta ser un mojón de referencia en el tiempo para definirse a sí mismos. Notan que se produjo un punto de inflexión que implicó la incorporación de de más leyes.

Yo me acuerdo que hace diez años el piso era muy bajo y hoy por hoy todas las comunidades de Noam respetan Shabat, todas las comunidades de Noam respetan kashrut (dieta kosher). En algunas kehilot (comunidades) se está comenzando a no cobrar en Shabat [las actividades para niños y adolescentes]. Y lo que Noam tiene que buscar es que esta escalerita siga creciendo, que el piso sea más alto (Entrevista a Jonathan, secretario de Noam, 24 años, 20 de abril de 2011).

Pareciera que esta posición intermedia entre el reformismo y la neo-ortodoxia que asume el movimiento masortí desafía los límites o fronteras que separan a los emprendedores que forman parte de esta red de confianza para diferenciarse de los extraños. Sin embargo, también algunos emprendedores y emprendedoras coinciden en que aunque la apropiación de la Ley Judía es selectiva, el cumplimiento debe ser menor. No se sienten identificados con las "posiciones extremas". No obstante, reconocen que si bien pueden estar en desacuerdo con el modo de apropiación, deben cumplir con los preceptos consensuados ya que de otro modo dejarían de ser masortí. El no cumplimiento implica convertirse en otra cosa.

Para los entrevistados, la educación no formal resulta ser un elemento constitutivo del movimiento masortí. Entienden que ejercer el rol de madrij los implica directamente dentro del movimiento. En términos de Tilly (2010), la educación no formal forma parte de los derechos y obligaciones que tienen los participantes de esta red.

Al consultarles respecto de cuáles son los pilares o preceptos que los hacen sentir parte del movimiento masortí, pudo notarse una diversidad de respuestas. Solo 2 casos, -los secretarios de Noam de dos períodos distintos-, respondieron según la 'carta'. Es decir, según el contenido ideológico (Lourau, 1970). En términos de Malinowski, "la carta es la idea que los miembros tienen de su institución, y la definición que la comunidad le da a ésta" (tomado de Lourau, 1970, p. 127). Explican que los principales preceptos son, en primer lugar el

\section{Revista Cultura \& Religión Vol. XIII, 2019 N 1 (enero-junio)}

Cómo citar este artículo: Lerner, V.C. (2019). "Los sentidos de pertenencia de los y las jóvenes que participan en el movimiento masortí en la Ciudad Autónoma de Buenos Aires. Percepciones sobre el movimiento y la "comunidad".

Revista Cultura \& Religión. Vol. 13(1). pp. 64-84. 
estudio de la Torá (Pentateuco) junto con espacios de lectura en los servicios religiosos y en los rezos diarios (mañana, tarde y noche). En segundo lugar, la observancia del Shabat entendiendo que su apropiación variará de acuerdo a cómo cada "comunidad" resuelva implementarla. Tercero, el cumplimiento del kashrut o dieta kosher. Cuarto, la centralidad del Estado de Israel entendiéndolo como el hogar nacional judío. Se reconocen como sionistas aunque asumiendo que la feligresía adopta lo que llamamos un sionismo no realizador, es decir que se apoya al Estado pero sin promover abiertamente la migración a dicho país. Por último, el precepto de Tikún Olam, que en hebreo significa "corregir al mundo". Se busca "mejorarlo" a través de las buenas acciones. La tzedaká, la justicia social, forma parte de esta "corrección del mundo"; no está asociada a la caridad sino a darle al necesitado lo que precisa que no siempre está vinculado con las urgencias económicas. Puede ser: visitar a algún enfermo, acompañar al prójimo en un proceso de duelo, ayudar a alguien a que se case o consiga una casa, etc.

En el resto de los emprendedores las respuestas fueron variadas. Muchas de ellas van en sintonía con esta 'carta'. Cada uno hace hincapié en alguna de estas cuestiones, no así en su totalidad. Opinan que les falta una definición clara y precisa de lo masortí y que esto es así debido a un problema de comunicación. Hay dificultad en explicar qué es. Si bien reconocen que están los medios para comunicar, por momentos el mensaje les resulta ambiguo.

No hay un lenguaje claro, hay muchas metas, tantas que los mareamos. No sabemos a dónde ir ni dónde invertir. Los jóvenes no son el futuro, son el presente. Hoy uno tiene que ir a casamientos de amigos en sinagogas ortodoxas o con un juez de paz o no van a circuncidar a sus hijos, así vamos perdiendo experiencias. Faltan cenas sabáticas exclusivas para jóvenes. Hay distancia entre rabinos y jóvenes. Está bien hablar bien del pasado, pero no con nostalgia sino con honores (Discurso del secretario de Marom en el Congreso Atid, Buenos Aires, agosto de 2011).

Para ellos, los preceptos o pilares que los hacen sentir parte del movimiento masortí es la educación no formal ya que a partir de ella pueden contribuir, "aportar su granito de arena", "ayudar al otro a ser mejor persona" cumpliendo de este modo con el último punto de la 'carta'. Inmediatamente asocian al movimiento con su forma de transmitir. Entienden que su pilar principal es la "cultura de transmisión". No identifican al movimiento masortí con el cumplimiento de preceptos específicos sino por medio de valores. Es "una forma de pensar y de ser", en otros términos, un ethos que implica una dimensión actitudinal; un conjunto de valores y motivaciones que remite a las cualidades morales del individuo, "ya sea a las disposiciones, valores, creencias, modos de ser y/o inclinaciones que generan conductas, prácticas y acciones" (Montero, 2012, p. 225). Como dice Becker (2014) lo que los vincula son normas generales con un alto grado de ambigüedad que puede resultar una guía en los individuos para llevar a cabo acciones generales no así en la realización de prácticas concretas. Esto permitiría problematizar cómo aspectos institucionales del movimiento como los valores, fragmentan la construcción identitaria de los y las jóvenes emprendedores. Puntualmente en esta respuesta se nota la distancia existente entre las

\section{Revista Cultura \& Religión Vol. XIII, 2019 N 1 (enero-junio)}

Cómo citar este artículo: Lerner, V.C. (2019). "Los sentidos de pertenencia de los y las jóvenes que participan en el movimiento masortí en la Ciudad Autónoma de Buenos Aires. Percepciones sobre el movimiento y la "comunidad".

Revista Cultura \& Religión. Vol. 13(1). pp. 64-84. 
premisas del movimiento masortí según su 'carta', con las percepciones que los jóvenes tienen del mismo. En sus argumentaciones se puede dar cuenta de cómo su estilo de vida secular incide en la forma de pensar su sistema de referencia.

Esto se hace más evidente cuando se les preguntó si llevaban a cabo algún precepto religioso en sus hogares. 3 casos que respondieron que hacen el rezo de Shajarit todas las mañanas ( 2 en sus hogares y 1 en su lugar de trabajo); 2 que respetan la dieta kosher y 2 se definieron como vegetarianos coincidiendo con las pautas del kashrut. El resto inmediatamente explicó que todos los preceptos religiosos los llevan a cabo en su "comunidad". A menos que trabajen o tengan que cursar alguna materia en la universidad, asisten al servicio religioso del viernes para celebrar el Shabat. El hecho de decidir ir a la sinagoga lo reconocen como una decisión resuelta en el ámbito privado para ejecutarla en lo público. Explican que en el ámbito privado no cumplen con preceptos religiosos salvo algunas prácticas en las festividades. Aclaran que más que preceptos, se trata de costumbres: hacer las cenas familiares para la Pascua Judía (Pesaj), el Año Nuevo (Rosh Ha Shaná) y al culminar el Día del Perdón (Iom Kipur), ingerir las comidas típicas de cada festividad (no comer harinas durante la semana de la Pascua o la manzana con miel para el Año Nuevo), ayunar durante el Día del Perdón, prender las velas de Jánuca y la colocación de la mezuzá (caja pequeña que contiene un pergamino con fragmentos del Deuteronomio que se coloca sobre el poste derecho de las puertas). 4 entrevistados contaron que sus familias hacen cenas sabáticas los viernes que incluyen el encendido de velas, la bendición de vino y de la jalá (pan trenzado) y la cena propiamente dicha. Aclaran que ellos no concurren porque van a la sinagoga.

Cuando se les preguntó si había momentos no religiosos que los hacían sentir parte del movimiento masortí, lo vinculan con los momentos de socialización tanto dentro de su organización como por fuera de ella. En primera instancia aparecen los espacios intercomunitarios propuestos por Noam, como ser capacitaciones sin contenido religioso (clases de improvisación, de primeros auxilios o de cualquier otra temática no vinculada con textos bíblicos), cenas, espacios de juego, etc. También los identifica el hecho de estar en "comunidad": compartir con sus amigos, la relación de familiaridad entre sus miembros, el reconocerse en la calle y saludarse. El ejercicio de la educación no formal que no siempre implica la transmisión de contenido religioso sino también con el crecimiento de los educandos, pautas de convivencia, etc. Por último, sienten que esto se da en los espacios de socialización que exceden a la red masortí como ser la escuela, los hogares/las familias, el club. Definen a esto como "estar dentro de un marco judío" que es posible mediante la interacción y la circulación de diversos ámbitos. También lo ven reflejado en la cultura a través de la comida, la música, la danza folklórica israelí, palabras o expresiones en idish, hebreo o sefaradíes. Esto último da cuenta que lo étnico también resulta ser un modo de identificación con lo judío.

\section{El sentido de formar parte de una "comunidad".}

\section{Revista Cultura \& Religión Vol. XIII, 2019 № 1 (enero-junio)}

Cómo citar este artículo: Lerner, V.C. (2019). "Los sentidos de pertenencia de los y las jóvenes que participan en el movimiento masortí en la Ciudad Autónoma de Buenos Aires. Percepciones sobre el movimiento y la "comunidad".

Revista Cultura \& Religión. Vol. 13(1). pp. 64-84. 
Al final de cada entrevista, se les preguntó qué significa sentirse parte de su "comunidad". La respuesta les resultaba sencilla y los entusiasmaba. Inmediatamente decían que era su lugar de pertenencia, su casa, su familia. Sienten que les ofrece apoyo y contención en momentos difíciles. Expresan un amor muy profundo por el espacio. Explican que los atravesó en su biografía, que allí conocieron a sus amigos y que en muchos casos conforman su grupo de pertenencia con los que comparten salidas, vacaciones, celebraciones, etc. Resaltan esa sensación de familiaridad y comodidad que viven allí dentro. Valoran que todos se conozcan, se saluden y sepan de la vida del otro. Incluso, encontrarse en el barrio, reconocerse y entablar una conversación; el tener un vínculo cara a cara o por teléfono para invitar a sus educandos a las actividades o para informarles a los padres sobre viajes y eventos especiales. Si bien los emprendedores y emprendedoras utilizan redes sociales para comunicarse y mostrar lo que hacen, recalcan que en este espacio las relaciones son de otra manera.

Yo siempre dije que quiero ser madrijá para devolver lo que me dieron a mí. Todos los años hermosos y la gente que conocí y a todos mis amigos. Yo también quiero que mis janijim tengan todo eso, yo también quiero ser madrijá (Entrevista a Cynthia, madrijá de Comunidad Nefesh, 18 años, 10 de febrero de 2016).

E:- Y ya para ir cerrando,¿qué significa para vos sentirte parte de Comunidad Le Olam?

L:- Significa escuchar una canción de Comunidad Le Olam y ponerme a cantar, encontrarme a alguien en la calle y ponerme a charlar de cualquier tema. Encontrarme algún janij(educando) por la calle y ponerme a hablar. Es muy graciosa la sensación pre majané (campamento) encontrarme a los chicos, no sé si viste que en Canning y Corrientes hay una "Tienda de dulces", algo así se llama y de repente ves a todos los janijim (educandos) de las comunidades de Villa Crespo. Y ves a la gente de Comunidad Le Olam comprando sus golosinas ahí y es el momento en el cual ya empezás a saborear el majané... (Entrevista a Lara, madrijá de Comunidad Le Olam 19 años, 8 de agosto de 2017).

Nuevamente, aparece la educación no formal como principal pilar. Manifiestan que su "comunidad" resulta ser un espacio de transmisión, de trascendencia y de realización. Que con ella pueden "devolver a la comunidad lo que habían recibido" y "ayudar a otros a encontrar su lugar en el mundo". En estas respuestas aparece un ethos que define el significado de pertenecer. A la vez, se sienten agradecidos con la misma porque gracias a ese rol ocupado pudieron romper con su timidez y tener confianza en sí mismos. Esto lo ven en el hecho de subir a un escenario, tomar el micrófono y hablar en público, en poder estar al frente de un grupo y dialogar con padres/adultos, etc.

En otras expresiones dan cuenta de lo religioso sin que ellos lo identifiquen de esa manera. La "comunidad" es un lugar que la aleja de sus obligaciones profanas como el trabajo y el estudio siendo un momento de encuentro con sus amigos y sus educandos. "Cortás con la semana", "es mi cable a tierra".

E:- ¿Qué significa para vos ser parte de Comunidad Menorá?

J:- No, qué significa. Mi lugar, mi casa. Para mi es eso. Es sentirme en mi lugar completamente, es mi cable a tierra (...) me despreocupaba de mi abuelo por ejemplo. Yo sé que ahora voy el viernes a

\section{Revista Cultura \& Religión Vol. XIII, 2019 Nº 1 (enero-junio)}

Cómo citar este artículo: Lerner, V.C. (2019). "Los sentidos de pertenencia de los y las jóvenes que participan en el movimiento masortí en la Ciudad Autónoma de Buenos Aires. Percepciones sobre el movimiento y la "comunidad".

Revista Cultura \& Religión. Vol. 13(1). pp. 64-84. 
Comunidad Menorá y me veo con Demi, con Chelo y con todos y esté mi abuelo como esté me olvido por lo menos dos horas de eso (...) Comunidad Menorá me dio mis amigos, que después salgo con ellos y me olvido y sigue siendo mi cable a tierra por ese sentido. Y de por sí fue a mí que me cambió como persona, me cambió no sé a quién le estoy agradecida (Entrevista a Jésica, madrijá de Comunidad Menorá, 20 años, 24 de enero de 2017).

En estas frases puede notarse cómo la "comunidad" representa momentos sagrados en su vida profana, aunque ellos asocien lo religioso con el cumplimiento de preceptos. De todos modos, cabe aclarar que si bien desde el plano discursivo, los emprendedores y emprendedoras señalan que al ingresar a la "comunidad" se da una ruptura completa entre lo sagrado y lo profano (Durkheim, 2008), en la práctica se puede notar que dicha ruptura no resulta ser tan tajante. Los emprendedores hablan acerca de su individualidad, de su vida cotidiana: cómo les fue en sus exámenes, si resolvieron sacar el registro de conducir, chismes, etc. Así, las fronteras entre lo sagrado y lo profano resultan más difusas. Si bien Parker (2008), piensa estos procesos para las religiones populares, puede observarse que estos se hacen extensivos al mundo masortí.

Cada emprendedor resalta que el sentimiento o el amor por su "comunidad" es mayor en comparación con otras "comunidades". Eso se ve expresado no solo en sus relatos sino también en la forma vehemente con la que cantan sus himnos inventados por ellos al igual que las canciones que hacen para los campamentos, el usar sus remeras con colores que los identifican, los rituales no halájicos en los campamentos, los fogones; todas prácticas en las que se reconocen como parte de su "comunidad" y que los diferencia de otras.

\begin{abstract}
Hacemos letras con estopa y se prende fuego y queda como Comunidad Shalom en fuego, es muy lindo, la ceremonia que hacemos, el himno de Comunidad Shalom, yo en los últimos años como janij(educando)lloraba con el himno, el himno de Comunidad Shalom era como "Oh". Los majanot (campamentos) en la playa también, la foto... en los últimos años comenzamos hacer la foto en la playa de los janijim (educandos) formando un Maguen David (Estrella de David) o alguna palabra en hebreo o algo así (...) las remeras de cada grupo, el merchandising de cada grupo, las canciones de todos los grupos (...) no sé si lo hacen en otras comunidades, sé que por ejemplo Comunidad Ajim no lo hace, que es que, hay como una competencia inter-área, donde hay que hacer un videoclip...(Entrevista a Pablo, madrij de Comunidad Shalom, 18 años, 4 de octubre de 2016).
\end{abstract}

En este sentido, los emprendedores y emprendedoras entienden a la "comunidad" como una sensación asociada a lo placentero. Coincidiendo con Bauman (2008) en las representaciones que tienen de su "comunidad" no aparecen los conflictos entre los miembros que la componen, las luchas simbólicas ni las contradicciones respecto de posicionamientos sobre distintos tópicos, por más que lo hayan marcado a lo largo de la conversación. Prima la noción de armonía. Cuando piensan qué significa formar parte de su "comunidad" apelan a una comunidad imaginada que se diferencia de la existente. En ella se evoca el paraíso al que desean volver. Allí logran obtener la seguridad, el aplomo y la confianza que el mundo exterior no les brinda.

Los emprendedores y emprendedoras de cada "comunidad" ven a sus colegas de otras como lo mismo y como lo diferente. El modo de apropiación de la Ley Judía define en ellos

\title{
Revista Cultura \& Religión Vol. XIII, 2019 N 1 (enero-junio)
}

Cómo citar este artículo: Lerner, V.C. (2019). "Los sentidos de pertenencia de los y las jóvenes que participan en el movimiento masortí en la Ciudad Autónoma de Buenos Aires. Percepciones sobre el movimiento y la "comunidad". Revista Cultura \& Religión. Vol. 13(1). pp. 64-84. 
un grado de judeidad entendiendo que se es "más judío" por incorporar mayor cantidad de preceptos religiosos.

E:- ¿Notás mucha diferencia en cómo piensa una comunidad de la otra?

C:- Sí, lo noté mucho más en el curso de Nofim(coordinadores) que hicimos que en el majané por ejemplo, Comunidad Le Olam siempre tiene que planificar con la Torá, todo para ellos es la Torá, y nosotros nunca hicimos nada (...) Me parece que es eso lo que hace la diferencia. Ellos son más judíos que nosotros y así.

E:- Y después por ejemplo ¿Comunidad Tefilá?

C:- También, es parecido a nosotros pero yo los veo a los otros más judíos que a nosotros (Chelo, madrij de Comunidad Menorá, 20 años, 18 de enero de 2017).

Esto se vio claramente en el cumplimiento con el Shabat el cual implica la prohibición de determinadas acciones como: prender fuego, tocar dinero, viajar, hacer un "uso excesivo de electricidad" al interior de cada "comunidad". Luego, cada una incorpora más especificidades o resuelve el cumplimiento de estas restricciones de manera diferente. Esto por momentos los desestabiliza por no lograr una coherencia entre el discurso masortí y sus prácticas concretas. Aparecen cuestionamientos, vacilaciones y tensiones en la construcción de sí mismos. No así cuando se trata de mostrar la pasión, los distintivos y rituales que no son halájicos pero que sí son propios de cada "comunidad". Los himnos, las canciones, las remeras, los fogones en los campamentos, son los muros que refuerzan esas unidades insulares que por momentos pueden ser quebrados y homogeneizados cuando se producen rituales religiosos que resultan ser trascendentales en los actores.

E:- ¿Y en qué momento vos sentís que se arma el movimiento?

T:- Y generalmente en las tefilot que cantamos las canciones a la luz de la luna, yo digo, “¡No! ¡Mirá este momento!". Después de bañarse los chicos están re cansados, pero son uno de los momentos que más te llenan. A mí, mirá, yo no soy tanto del templo, pero ahí... (Entrevista a Tali, madrijá de Comunidad Menorá, 18 años, 27 de abril de 2017).

\section{Reflexiones finales}

A partir de lo desarrollado puede notarse la complejidad que existe en la definición que hacen los emprendedores y emprendedoras para definir su pertenencia y su vínculo con esa pertenencia. Establecen distintos niveles. Uno más general que refiere a su percepción sobre el movimiento masortí y uno más específico que es el de la "comunidad". Para poder pensarse en el movimiento masortí primero recalcan que pertenecen a una "comunidad" en particular. Por eso, resaltamos que lo masortí es vivido de forma insular.

El despliegue de las dimensiones que conforman al movimiento masortí como una red de confianza permite mostrar los acuerdos y las tensiones que existen en sus definiciones. Permanentemente, negocian con lo secular y lo religioso para legitimar o cuestionar su pertenencia. Esto puede verse en cómo denominan al movimiento en el que, por un lado, resulta ser un sinónimo de libertad donde prima lo secular y, por el otro, es entendido como

\section{Revista Cultura \& Religión Vol. XIII, 2019 N 1 (enero-junio)}

Cómo citar este artículo: Lerner, V.C. (2019). "Los sentidos de pertenencia de los y las jóvenes que participan en el movimiento masortí en la Ciudad Autónoma de Buenos Aires. Percepciones sobre el movimiento y la "comunidad".

Revista Cultura \& Religión. Vol. 13(1). pp. 64-84. 
algo ambiguo donde lo religioso debería cobrar mayor presencia. Reconocen que se trata de un movimiento halájico aunque son los momentos no religiosos los que los identifican. Lo religioso se produce en lo público no así en lo privado. Allí los rituales religiosos cobran un sentido específico. No obstante, se identifican con lo masortí no por el cumplimiento de leyes sino como una forma de ser en un mundo secular. Aunque, cumplir con ellos en "comunidad" implica definirse y construir fronteras con "otros" dentro yfuera del movimiento.

Lo mismo ocurre con la educación no formal. Se trata de la práctica por excelencia que los hace sentir parte del mundo masortí. Forma parte de sus derechos y obligaciones. Es a partir de ella que pueden acercarse los pilares de la 'carta', pero a la vez la identifican como una práctica secular o más ligada al mundo de los valores.

Por el contrario, sentirse parte de su "comunidad" no presenta dichas tensiones aunque a lo largo de las conversaciones las hayan mostrado. Aunque el movimiento masortí avale esta descentralización y esta autonomía relativa respecto de la aplicación de la Ley, para los jóvenes resulta ser un conflicto para pensarse como movimiento. Dan cuenta de las constantes negociaciones que se deben hacer cuando diferentes "comunidades" conviven en un mismo espacio. En este punto en la forma de organización institucional masortí aparecen aspectos desinstitucionalizantes. La autonomía relativa de las "comunidades" junto con las negociaciones entre diferentes poderes dificulta en los jóvenes poder hacer una síntesis y reconocer un movimiento.

Pese a ello, los jóvenes perciben que la "comunidad” es un lugar idílico, propio, donde pueden desarrollar sus vínculos y relaciones y a la vez conformar un proyecto. Es el espacio donde desplegaron sus trayectorias, que los contiene y los sostiene. En sus respuestas no aparecen las contiendas, los personalismos, las contradicciones. La idea de comunidad trasciende los conflictos y es la que les permite conectarse con el movimiento masortí en general, aunque eso implique levantar muros con emprendedores de otras "comunidades".

\section{Referencias Bibliográficas}

Álvarez, H. \& Strusbeg, M. (2003). “Judíos". En Guía de la diversidad religiosa de Buenos Aires (81-98). Floreal Forni, Fortunato Mallimaci \& Luis Cárdenas (Coordinadores). Volumen 2. Buenos Aires: Ed. Biblos.

Bauman, Z. (2008). Comunidad. En busca de seguridad en un mundo hostil. Madrid: Siglo XXI.

Baumann, G. (2001). El enigma multicultural: un replanteamiento de las identidades nacionales, étnicas y religiosas. Barcelona: Paidós.

Becker, H. (2014). Outsiders: Hacia una sociología de la desviación. Buenos Aires: Siglo Veintiuno Editores.

Revista Cultura \& Religión Vol. XIII, 2019 № 1 (enero-junio)

Cómo citar este artículo: Lerner, V.C. (2019). "Los sentidos de pertenencia de los y las jóvenes que participan en el movimiento masortí en la Ciudad Autónoma de Buenos Aires. Percepciones sobre el movimiento y la "comunidad".

Revista Cultura \& Religión. Vol. 13(1). pp. 64-84. 
Bokser Liwerant, J. (2011). "Los judíos de América Latina. Los signos de las tendencias: Juegos y contrafuegos". En Pertenencia y alteridad. Judíos en/de América Latina: Cuarenta años de cambios (115-164). Haim Avni, et. al. (Compiladores). Madrid: Iberoamericana Vervuert.

Bourdieu, P. (1990). Sociología y Cultura. Grijalbo: México.

Bourdieu, P. (2006).“Génesis y estructura del campo religioso”. Relaciones. Estudios de historia y sociedad. Volumen 27, N.108. El Colegio de Michoacán, A. C., Zamora, México, pp. 29-83.

Brauner, S. (2009). Ortodoxia religiosa y pragmatismo político (los judíos de origen sirio). Buenos Aires: Lumiere.

Camargo Crespo, Ó. (1999). "Los judíos de Madrid. Una aproximación desde sus "ilustrados"". La Gazeta de Antropología. N. 15. pp. 1-29. Ver en: http://www.gazeta-antropologia.es/?p=3445

Caro, I. (2006). "Comunidades judías y surgimiento de nuevas identidades: el caso argentino". Persona y Sociedad. Volumen 20, № .3. Universidad Alberto Hurtado, pp. 43-72.

Carozzi, M. J. (1999). “La autonomía como religión: la nueva era”. En: Alteridades. Volumen 9, $\mathrm{N}^{\circ} .18$. pp. 19-38.

Ceriani, C. (2013). "La religión como categoría social: encrucijadas semánticas y pragmáticas”. Revista Cultura y Religión. Volumen 7, №. 1. Enero-junio, pp. 10-29.

Cohen, G. (1987). "Conservative Judaism". En Contemporary Jewish religious thought. Original essays on critical concepts, movements, and beliefs (pp. 91-99). Arthur Cohen \& Paul Mendes-Flohr (eds.). New York: Charles Scribner's Sons.

Chami Paz, D.L; Scundieri, M. \& Imhoff, D. (2018). “Abordaje psicosocial de la identidad judía en jóvenes de una escuela de la colectividad masortí de córdoba, argentina”. En Revista Cultura \& Religión, $\mathrm{N}^{\circ}$ 6, Volumen 12. Pp. 4-27.

Della Pergola, S. (2011). “¿Cuántos somos hoy? Investigación y narrativa sobre población judía en América Latina". En Pertenencia y alteridad. Judíos en/de América Latina: Cuarenta años de cambios (305-340).Haim Avni, et. al. (Compiladores). Madrid: Iberoamericana Vervuert.

Denscombe, M. (1999). The Good Research Guide for small-scale social research projects. Buckingham: Open University Press.

Durkheim, E. (2008). Las formas elementales de la vida religiosa. México: Alianza Editorial.

Elkin, J. (1986). “The Argentine Jewish Community in Changing Times". Jewish Social Studies. Volumen 48, $\mathrm{N}^{\circ}$. 2. Spring, pp. 175-182.

Erdei, E. (2011). "Demografía e identidad: a propósito del estudio de población judía en Buenos Aires". En Pertenencia y alteridad. Judios en/de América Latina: Cuarenta años de cambios (341-364). Haim Avni, et. al. (Compiladores). Madrid: Iberoamericana Vervuert.

Fainstein, D. (2006). Secularización, Profecía y Liberación: La desprivatización de la religión en el pensamiento judio contemporáneo. Un estudio comparativo de 
sociología histórica e historia intelectual. Tesis doctoral en Ciencias Políticas y Sociales de la Universidad Nacional Autónoma de México. México D.F. México.

Freire, P. (2005). Pedagogía del oprimido. México: Siglo XXI Editores.

Frigerio, A. (2016). "La ¿nueva? Espiritualidad: ontología, epistemología y sociología de un concepto controvertido". Ciencias Sociales y religión. Volumen 18, N. 24. Agosto, pp. 209-231.

Giménez Béliveau, V. (2016). Católicos Militantes. Sujeto, comunidad e institución en la Argentina. Buenos Aires: Eudeba.

Hall, S. (2011). "Introducción: ¿Quién necesita una identidad?” En Cuestiones de identidad cultural (pp. 13-39). Stuart Hall \& Paul du Gay (Compiladores.). Buenos Aires: Amorrortu.

Hervieu Léger, D. (2004). « Las comunidades bajo el reinado del individualismo religioso ». En El peregrino y el convertido. La religión en movimiento (164-210). México: Ediciones del Helénico.

Hupert, P. (2014). Judaísmo Líquido. Multiculturalismo y judios solitarios. Buenos Aires: Editorial Biblos.

Jmelnizky, A. \& Erdei, E. (2005). La población judía en Buenos Aires: estudio sociodemográfico. Buenos Aires: AMIA.

Jozami, G., Bargman, D. \& Bialogorski, M. (1998). "Arabs, Jews and Koreans in Argentina: A Contemporary Perspective of Different Types of Social and Symbolic Insertion". Anthropological Journal on European Cultures. Volumen 7, №. 2. pp. 87-105.

Kepel, G. (1995). La revancha de Dios. España: Grupo Anaya S.A.

Kornbluth Nachtygal, S. (2012). Judaísmo y espacio cotidiano: El caso de los judíos ashkenazím en Santiago de Chile. Tesis de grado en Antropología Social, Universidad de Chile. Chile. Ver en: http://repositorio.uchile.cl/bitstream/handle/2250/116461/TESIS.pdf?sequence=1

Lourau, R. (1970). El análisis institucional. Buenos Aires: Amorrortu.

Margulis, M. \& Urresti M. (2008). "La juventud es más que una palabra”. En La juventud es más que una palabra (13-30). Mario Margulis, (editor). Buenos Aires: Biblos.

Martínez Ariño, J. (2011). Las comunidades judías contemporáneas de Cataluña. Un proceso sociológico a través de los procesos de construcción y transmisión identitaria. Tesis doctoral por la Facultat de Ciéncies Politiques I de Sociologia, Universitat Autónoma de Barcelona. España Ver en: https://ddd.uab.cat/pub/tesis/2011/hdl_10803_113490/jma1de1.pdf

Martínez Lozano, C. \& Solís Domínguez, D. (2009). "El entorno escolar y familiar en la construcción de significaciones de género y sexualidad en jóvenes de Guadalajara". Revista de Estudios de Género, La ventana. Volumen 3, N²9. pp. 146-183.

Melamed, D. (2000). Los judíos y el menemismo. Un reflejo de la sociedad argentina. Buenos Aires: Editorial Sudamericana.

Montero, A. (2012). "Los usos del ethos. Abordajes discursivos, sociológicos y políticos". Rétor. Volumen 2, $\mathrm{N}^{\circ}$. 2. pp. 223-242.

\section{Revista Cultura \& Religión Vol. XIII, 2019 Nº 1 (enero-junio)}

Cómo citar este artículo: Lerner, V.C. (2019). "Los sentidos de pertenencia de los y las jóvenes que participan en el movimiento masortí en la Ciudad Autónoma de Buenos Aires. Percepciones sobre el movimiento y la "comunidad".

Revista Cultura \& Religión. Vol. 13(1). pp. 64-84. 
Mosqueira, M. (2014). "Santa Rebeldia". Construcciones de juventud en comunidades pentecostales del Área Metropolitana de Buenos Aires. Tesis doctoral en Ciencias Sociales, Universidad de Buenos Aires. Buenos Aires. Argentina.

Parker, C. (2008). "Mentalidad religiosa post-ilustrada: creencias y esoterismos en una sociedad en mutuación cultural". En América Latina y El Caribe. Territorios religiosos y desafíos para el diálogo (334-364). Aurelio Alonso (Compilador). Buenos Aires: CLACSO.

Reguillo Cruz, R. (2000). Emergencia de las culturas juveniles. Estrategias del desencanto. Buenos Aires: Norma.

Romero Ocampo, J. (2010). “Jóvenes y religión en un mundo de cambio. El caso de los jóvenes chilenos". Ciencias Sociales y Religión. Año 12, $\mathrm{N}^{\circ} .12$. Porto Alegre, pp. 147-156.

Rosemberg, D. (2010). Marshall Meyer el rabino que le vio la cara al diablo. Buenos Aires: Capital Intelectual.

Rubel, Y. (2011). "La red educativa judía de la Argentina (1967-2007)". En Pertenencia y alteridad. Judios en/de América Latina: Cuarenta años de cambios (529-562). Haim Avni, et. al. (Compiladores). Madrid: Iberoamericana Vervuert.

Sautu, R. (1999). El método biográfico: la reconstrucción de la sociedad a partir del testimonio de los actores. Buenos Aires: Belgrano.

Schenquer, L. (2012). Actitudes sociales en dictadura: Estudio sobre las dirigencias de DAIA $y$ de las instituciones religiosas liberales durante el último régimen militar (19761983). Tesis doctoral en Ciencias Sociales de Universidad de Buenos Aires. Buenos Aires. Argentina.

Schutz, A. (1974). El problema de la realidad social. Buenos Aires: Amorrortu.

Senkman, L. (2007). "Ser judío en Argentina: las transformaciones de la identidad nacional". En Identidades judías, modernidad y globalización (403-454). Paul Mendes-Flohr, Yom Tov Assis \& Leonardo Senkman (Editores). Universidad Hebrea de Jerusalén: Lilmod.

Setton, D. (2015) "Algunas claves para el estudio sociológico de los judaísmos contemporáneos”. Revista Ciencias Sociales. N $^{\circ} .88$. Universidad de Buenos Aires, pp. 58-62. Ver en: http://ri.conicet.gov.ar/handle/11336/20061

Tilly, C. (2010). Confianza y gobierno.1ed. Buenos Aires: Amorrortu.

Weil, A. (1988). Orígenes del movimiento judío conservador en la Argentina.Buenos Aires: Ediciones Seminario Rabínico Latinoamericano.

Weiss, A. (1988). The Decline and Rise of Jewish Life in Argentina 1970-1987. New York: Princeton.

Yalonetzky Mankevich, R. (2016). "Nosotros" y "los otros": peruanos judíos en la ciudad de Lima (1944-2014). Tesis doctoral en Sociología, Pontificia Universidad Católica del Perú. Perú. Ver en: http://tesis.pucp.edu.pe/repositorio/handle/123456789/7250 